\title{
Transport, Energy Conservation and Energy Efficiency in Buildings Explored as Situations of Opportunity for City Transformation
}

\author{
Aleh Kliatsko and Per Lundqvist
}

\begin{abstract}
This paper presents methodological developments and findings from the on-going research project entitled Situations of Opportunity in the Growth and Change of three Stockholm City Districts, called SitCit for short. In this project a future studies approach is used to create scenarios of more sustainable Stockholm City Districts (Bromma, Rinkeby, Södermalm) formulated as an overall $60 \%$ reduction in energy use in private transports, residential multifamily buildings and citizens' everyday life by the year 2060. Increased energy efficiency energy usage systems (EUS's) and conservation of services and functions will lead to reduced dependency on fossil fuels and lower $\mathrm{CO}_{2}$ emissions. In order to evaluate these two specific goals are set for the project: the average primary energy usage (power) per capita should not exceed $2 \mathrm{~kW}$ per person and the $\mathrm{CO}_{2}$ emissions per capita should not exceeded 1 ton per year.

The paper describes issues of energy use as consequence of human activities in cities and especially situation where the opportunities for change are significant.
\end{abstract}

Index Terms-Bottom-up approach, energy conservation, human activity system (HAS), situation of opportunity (SitOpp).

\section{INTRODUCTION}

The energy need is increasing worldwide together with the awareness of the climate change issue. Today, more than half of the world's population lives in cities and the urbanization are still increasing rapidly. This reinforces the importance of reaching a more sustainable development in urban areas.

The urbanization is in itself creating a high pressure on ecosystems. But in the same time, urbanization opens up new possibilities for improving sustainability. The dense city areas are idealistic for implementation of large technical systems such as public transport, car sharing system, energy efficient buildings, district heating/cooling, lifestyle and behavioural changes by increasing knowledge (understanding) and environmental awareness of the occupants.

Many recent projects indicate that it is technically possible to build new sustainable cities (for instance in the Middle East and North Africa Region (MENA), in China (for instance, a new district in the Chinese city of Wuxi) and in the United Arab Emirates [1]. For most countries, it is however not an option to build new cities, rather the

Manuscript received December 10, 2012; revised March 12, 2013.

Aleh Kliatsko and Per Lundqvist are with Royal Institute of Technology, Brinellvägen 68, Stockholm, 100 44, Sweden (e-mail: aleh.kliatsko@energy.kth.se). challenge is to transform the infrastructure and technical systems that already exist. Achieving a significant reduction in primary energy use in buildings, requires a thorough understanding of what energy savings can be made in this sector [2]. Sustainable development policies such as the Swedish Environmental Quality Objectives indicate the way forward, but how can researcher's planners and other stakeholders address the issue of sustainable development in a systematic way? This task is cross-disciplinary and nobody can handle the complexity with one organization. New tools and processes are therefore necessary for city planning and energy system planning where various competencies among the stakeholders can be pooled as resources in the knowledge formation process.

\section{BRIEF INTRODUCTION TO THE SITCIT PROJECT}

In this cross-disciplinary research project, SitCit, it is formulated as a challenge:

How can the primary energy use of three contrasting Stockholm City districts be reduced to a sustainable level in fifty years from now? Two indicators are chosen, primary energy and $\mathrm{CO}_{2}$ emissions. Is it possible to create the $2000 \mathrm{~W}$ society in Stockholm [3]? How big are the lowest possible associated $\mathrm{CO}_{2}$ emissions that can be achieved? Energy is here expressed as yearly average power per capita. $2000 \mathrm{~W}$ corresponds to $17520 \mathrm{KWh}$ per person. Regarding Statistics Sweden, the last 10 years the average energy use has been around $44000 \mathrm{kWh}$ per person and year, and thus the energy use needs to be decreased by approximately $60 \%$ for the $2 \mathrm{~kW}$-target to be met, and $\mathrm{CO}_{2}$ emissions in Sweden for 2008 per capita is 5,3 metric tons per capita [4].

The three cases (one in each district) initially chosen in the project can be described with a series of "What if"-questions to identify the Situation of Opportunity (SitOpp) being studied particularly:

- $\quad$ Case I: Low-energy alternatives to private transports in Bromma City District. What can be changed in transport systems and users' habit? More specifically: What if the residents of Bromma were prepared to in part substituting their use of private cars for a car sharing system combined with improved public transport?

- Case II: Substantially increased energy efficiency through planned refurbishment of multifamily buildings in the Rinkeby City District in Stockholm and improved service efficiency through changing human behaviour to rational sustainable lifestyle. How great is the potential of human behavior change concerning energy use in everyday life? 
- $\quad$ Case III: Innovative ICT for decreased energy use in residential buildings and private transports in Södermalm City District [5].

\section{The Situation Of OpPoRtunity CONCEPT (SitOpP)}

While studying the development and growth of cities, certain segments in time are considered more important than others. During these "formative moments" or "policy windows" stakeholders are given new unique opportunities to implement change (if they can see it). For obvious reasons they are easier to identify afterwards. Such a historical Situation of Opportunity is defined as: "A period in the city's development when a limited number of actors planned and implemented a consistent set of measures that profoundly and lastingly influenced the future growth of the city - changing its built environment and transport infrastructure, its institutional set-up and its citizens' ways of life" [6].

Thus, Situations of Opportunity are periods in the growth and change of a city when inertia against change is low, and its actors' pooled freedom of action - the Situation's Field of Options - is wide. The link between sustainable development and urbanization is approached by way of considering the following questions below.

The three main questions in the SitCit project are:

- What can be changed?

- How much can it change - which is the possible extent of change? How much primary energy $(\mathrm{kW} / \mathrm{J} / \mathrm{KWh})$ and fossil fuels ( $\mathrm{CO} 2$ equivalents) can be saved? This is assessed by modelling the Situation)

- By whom is changed guided/managed Transformative Network Governance (which stakeholders are present?)

- When - in Situations the What and the Who are identifiable, complexity is manageable [5].

These questions are elaborated methodologically by the three activities: Actor analysis (stakeholder analysis), qualitative and quantitative modeling (Fig. 1).

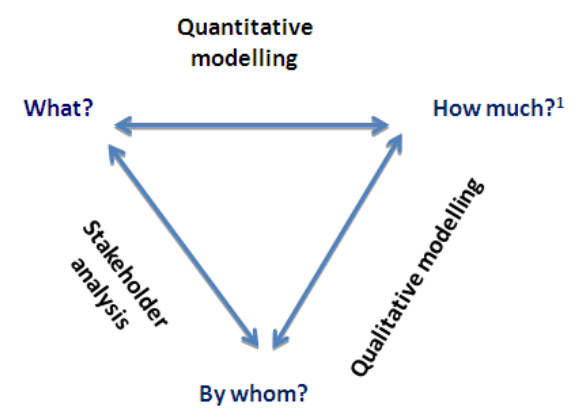

Fig. 1. Methodological questions and relations between

The stakeholder analysis explores what can change and by whom. The qualitative modelling uses the stakeholders' points of view to build the foundation for the quantitative modelling. Given the case at hand, what measures should be included in the SitOpp model? Which actors can make these things happen and therefore should be represented in the model's user interface? To exemplify, measures could be extra insulation of facades or persuasion that leads to residents reducing their energy use, actors involved could be the real estate owners concerning the facades and the residents concerning changes of habit. Energy provides city planners could be represented with their respective fields of influence. Finally, the quantitative modelling gives the identified actors a tool to quantitatively simulate the outcome of various combinations of decisions or options.

\section{Human ACTIVITy SyStem (HAS) MEthodology FOR RINKEBY CASE STUDY}

Baccini and Brunner [7] arrange all services in basic processes with the purposes to nourish, to clean, to reside and work, or to transport and communicate. A similar service-orientated approach is presented by Höjer et al. [8], using the household as point of departure. All household functions and activities, and thus their energy use, are allocated to one of the following categories or so-called household functions: Personal, Residence, Food, Care, Common, Support, and Personal.

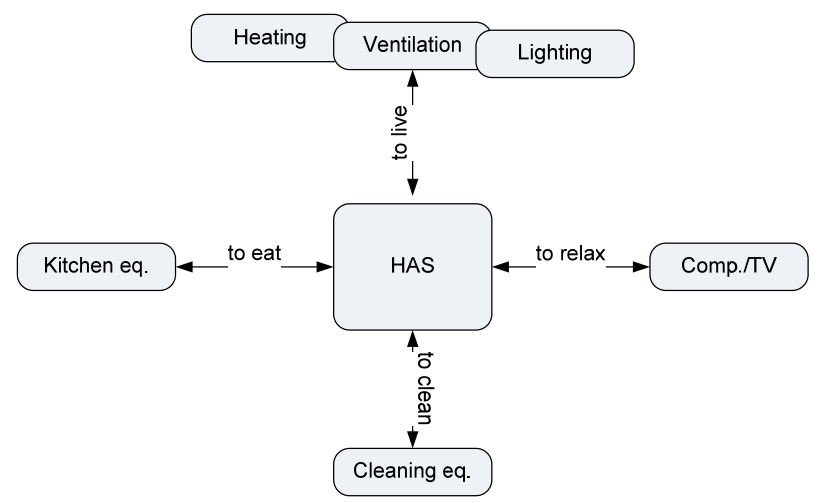

Fig. 2. Qualitative Model of a multifamily house (for Rinkeby case study).

Based on these bottom-up approaches for energy systems, the fundamental human activities (HAS) are related to housing were identified as: "Living", "Eating", "Relaxing" and "Cleaning". Each activity requires the use of different technical systems and these systems use energy (EUS). The relationship between the above mentioned activities and these technical systems is shown in Fig. 2 [9].

\section{V.BOTTOM-UP APPROACH ON ENERGY}

Increasing energy efficiency has for a long time been identified as an important aspect of solving climate change issues. A classical point of view is that this efficiency is the ratio of useful energy divided by primary energy. However, most people do not require energy but rather services such as good indoor climate, transportation and communication. In this research an alternative approach is taken by identifying the Human Activity System as the driver of services demand. These services have to be produces by Energy usage systems, EUS, the users of energy.

The research, presented in this paper, has in particular a special emphasis on energy services, based on the assumption that a deeper understanding of the user side would help to make energy systems more sustainable, especially in the context of energy efficiency analysis and policy. 


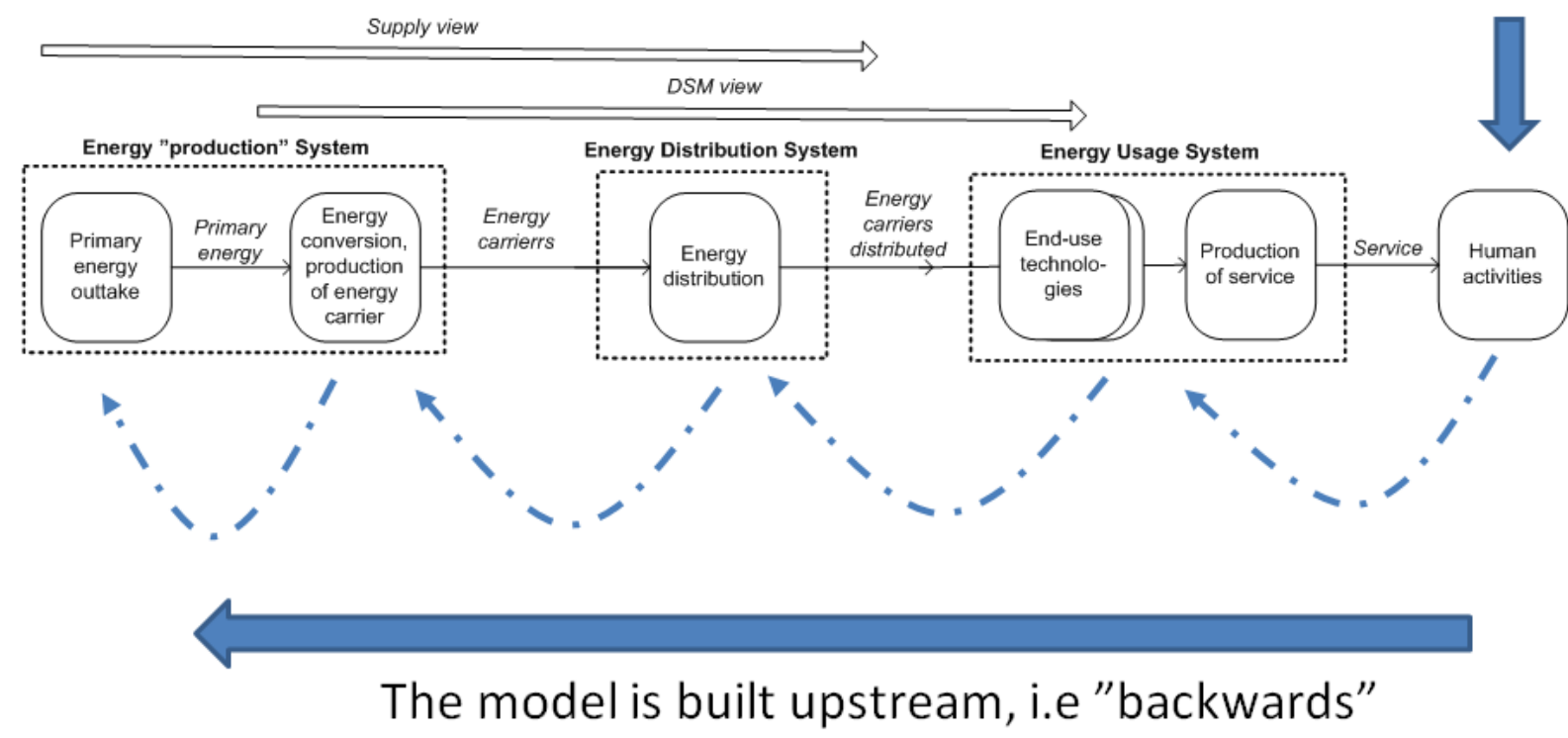

Fig. 3. Traditional top-down perspectives on the energy system, complemented with the user side [10]. SPM - Service Production Model (Conceptual)

Thus, it is important to include into account the users of the system. Since the standard approach to energy system analysis typically overlooks the importance of the user and the user's ability to act. This means that most energy systems operate solely on the basis of the conceived "demand" measured in KWh's and not by the users' needs in terms of Services.

\section{CONCLUDING}

Using Situations of Opportunity, or any other type of transformative event, as the basis for scenario studies have not been done before. In previous studies, the Situations concept has been used as a tool to delimit and analyze case studies of historical transformative events [11]-[14].

Working with the Situation of Opportunity concept, the researcher is asking a "what if"-question that refers to a desirable situation in the future when Sustainable Urban Development goals have been implemented. This "what if"-question is therefore a combination of assumptions on a future situation and the more concrete objects that are needed and must be available to reach the aim. The definition contains words referring to objects that need to be developed or changed (What), stakeholders or actors of change (Who), instants (When), and a measure for the improvement of sustainable development (How much each SitOpp can contribute to achieve low carbon and low energy objectives). Thus, the concept integrates those four dimensions.

During a SitOpp it is easier to implement changes than "on the average". These changes should also lead to long-term improved Sustainability. The research in the project is focused on investigating the importance of the user side of energy usage system (EUS), and what's role of user behavior in improving the efficiency of energy use. Energy use in buildings depends, in particular, on user behavior and lifestyles. The factors as the age of occupants, their habits and their income levels affect behavior and accordingly energy use. The purpose of the Bromma SitOpp is to explore how change in transport systems and users' habit of Bromma city district in western Stockholm, by taking advantage of arisen situations of opportunity when stakeholders have a greater chance of influencing the city's development towards more Sustainable Urban Development. The effective use of Information and Communication Technology (ICT) has a great potential in decreasing energy use. Smart ICT applications can, for instance, be used to influence the user behaviors by providing information on energy use or environmental cconsequences.

Each studied SitOpp (Bromma, Rinkeby, and Södermalm) enables a significant step in the transition from today's level of energy use to the $2000 \mathrm{~W}$ society and it enables us to test the modeling approach on real and realistic cases.

\section{REFERENCES}

[1] Masdar City. (2010). [Online]. Available: http://www.masdarcity.ae/en/

[2] G. Haughton and C. Hunter, "Sustainable Cities," Antony Rowe LTD. England, Eastborne, 2004.

[3] P. A. Haldi and D. Favrat, "Methodological aspects of the definition of a 2kW society," J. Energy, no 31, pp. 3159-3170, 2006.

[4] Statistiska centralbyrån. (2012). [Online]. Available: Statistiska centralbyrån: http://www.scb.se/

[5] Ö. Svane, et. al. (2012). Situations of Opportunity in the Growth and Change of three Stockholm City Districts. [Online]. Available: http://www.kth.se/abe/om skolan/organisation/inst/2.1233/2.3377/sit uations-of-opportunity-in-the-growth-and-change-of-three-stockholmcity-districts-1.13974.

[6] Ö. Svane, S. Gustafsson, J. Wangel, D. Jonsson, M. Höjer, P. Lundqvist, J. Palm, and C. Weingaertner, "Situations of Opportunity in City Transformation - enriching evaluative case study methodology with scenarios and backcasting, exploring the sustainable development of three Stockholm city districts," presented at ENHR 09 Conference, Prague, 2010.

[7] P. Baccini and P. H. Brunner, Metabolism of the anthroposphere, Berlin: Springer, 1991. 
[8] M. Höjer, A. Gullberg, and R. Pettersson, "Images of the future city - time and space for sustainable development," Springer, 2011.

[9] A. Kliatsko, P. Lundqvist, Ö. Svane, J. Arias, and O. Shafqat, "A Bottom-up approach on Human Activity System (HAS) modelling," in Proc. Third International Engineering Systems Symposium - CESUN 2012, the Delft University of Technology (TU Delft), 18-20 June 2012.

[10] D. Jonsson, S. Gustafsson, J. Wangel, M. Höjer, P. Lundqvist, Ö. Svane, "Energy at your service: highlighting energy usage systems in the context of energy efficiency analysis," J. Energy Efficiency, 2010.

[11] C. Weingaertner, Ö. Svane, and B. Brikell, "Daladala buses deregulated - analyzing urbanization's Situations of Opportunity through a Tanzanian example," International Journal of Sustainable Development and Planning, vol. 3, no. 1, WIT Press, 2008.

[12] Ö. Svane. (2007). Situations of Opportunity - Hammarby Sjöstad and Stockholm City's Process of Environmental Management; Accepted, Corporate Social Responsibility and Environmental Management, Wiley. [Online].

Available: www3.interscience.wiley.com/cgi-bin/jissue/110497535.
[13] C. Weingaertner and Ö. Svane, "MAMMUT - Managing the Metabolism of Urbanization: Testing theory through a pilot study of the Stockholm Underground," Sustainable Development, vol. 14, no. 5, John Wiley \& Sons Ltd, 2006.

[14] C. Weingaertner, "Analyzing Synergies between Urbanization and Sustainable Development," Licentiate Thesis in Infrastructure, Stockholm, Sweden, 2005.

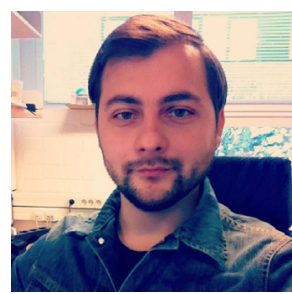

Aleh Kliatsko is a $\mathrm{PhD}$ candidate at the Department of Energy Technology of the Royal Institute of Technology, Stockholm, Sweden. A. $\mathrm{K}$. is involved in the SitCit project, Situations of Opportunity in the Growth and Change of three Stockholm City Districts. 